\title{
La democratización del libro: desde la piratería a los monopolios*
}

\section{The book democratization: from piracy to monopolies}

\author{
ROBERT DARNTON \\ Harvard University \\ robert_darnton@harvard.edu
}

\section{RESUMEN}

En esta nota, Robert Darnton, renombrado historiador cultural y del libro, comparte unas reflexiones en torno a esta invención y el devenir histórico de su circulación comercial. Comentando la piratería de libros de los siglos XVII y XVIII y los intentos contemporáneos de plataformas como Google de crear repositorios virtuales, Darnton pone en debate la tensión que existe entre los derechos de autor y la democratización de la lectura a través de una mayor accesibilidad a los libros. Palabras clave: libro, piratería, monopolio, derechos de autor, historia del libro

\section{ABSTRACT}

In this note, Robert Darnton, renowned culture and book historian, shares some reflections around the book invention and the historical evolution of its commercial circuits. By commenting the XVIIth and XVIIIth centuries book piracy and the recent attempts of platforms such as Google of creating open virtual libraries, Darnton brings up the debate surrounding the tension between the copyright and the democratization of reading by making books more accessible to everyone. Keywords: book, piracy, monopoly, copyright, book history

*Traducción de Adrián Lerner Patrón. 
Como El amor en los tiempos del cólera, el libro en los tiempos de la covid-19 nos trae alegría, fantasía y alivio. Nunca hemos leído tantos libros como en los últimos doce meses. Por mi parte, me zambullí en Guerra y paz, y pasé semanas deliciosas frecuentando a los rusos de la época de Napoleón. Después de terminar el texto, hubiese querido que fuera aun más largo, lo que me llevó a repensar mi relación con los libros, en general.

Obligado, como todo el mundo, a confinarme y a trabajar frente a la pantalla de una computadora, aproveché mis nuevos tiempos de ocio para regresar a mi biblioteca. Guerra y paz me hizo redescubrir el placer de pasar las páginas y sentir el papel mientras devoraba la narración de Tolstói. El códice, me dije, es la más bella invención de la humanidad. El reemplazar el volumen (o biblion, el libro en forma de rollo) hace dos mil años nos permitió recorrer un texto hojeándolo y creó la posibilidad de reunir un gran texto en un solo volumen. «Mega biblion, mega kaken» (gran libro, gran pena) decía Calímaco alrededor del año 260 antes de Cristo, ya que un biblion no podía contener más que un texto reducido y hacía falta manipular gran número de biblia para leer un libro tan largo como La Odisea. Hubiese tenido que desenrollar varias docenas de biblia o volumen para leer Guerra y paz. El códice, vehículo esencial de la Biblia, expandió el cristianismo por todas partes del mundo y, de modo general, se puede decir que hizo la cultura accesible a poblaciones enteras.

La democratización del acceso a la literatura es el tema central del libro que acabo de publicar con Gallimard, Editer et pirater. Le commerce des livres en France et en Europe au seuil de la Révolution. Fue en el siglo XVIII que el libro desbordó los límites de la élite y se comenzó a expandir a un gran público. Ello fue posible gracias a la piratería.

Me explico: durante el siglo XVII, tuvo lugar una guerra comercial entre los libreros-editores de París y los de las provincias de Francia, especialmente Lyon. El Estado de Luis XIV intervino a favor de la comunidad de libreros e impresores de París al otorgarles un monopolio sobre los privilegios de los libros. Excluidos del mundo de la edición, los provincianos quedaron reducidos a las librerías y, para siglo XVIII, se abastecían recurriendo a editores de libros franceses establecidos 
en el extranjero, en la que llamo una «Media Luna Fértil», que iba de Ámsterdam a Bruselas, Lieja, Renania y Suiza. Fue allí donde floreció la piratería, porque no había derechos de autor internacionales y los falsificadores podían reimprimir legalmente los libros producidos en Francia y luego hacerlos pasar como contrabando por todo el reino.

Sin embargo, el costo de producción en el extranjero era mucho menor que en París, gracias a los precios del papel y de la mano de obra, por no mencionar los pagos por el manuscrito. Existió, entonces, una alianza natural entre las casas de edición extranjeras y los libreros de las provincias. Además, los editores parisinos estaban obligados por los códigos de la librería a producir libros de alta gama, lo que constato cuando los consulto - papel de calidad, márgenes generosos y una disposición aireada de la página. Los piratas menospreciaban tales estándares, a los que llamaban el «lujo tipográfico». Ellos utilizaban papel barato, eliminaban las ilustraciones y no dudan en cortar el texto, a veces anunciando (falsamente) una edición "corregida y aumentada por el autor».

Durante mi confinamiento, pensé seguido en los aspectos físicos de los libros, ellos también confinados en bibliotecas cerradas a los investigadores. En tanto objetos producidos en el siglo XVIII, los libros expresan las visiones distintas del público a que apuntaban los editores. Un volumen impreso por un pirata marginal de Génova -JacquesBenjamin Téron, por ejemplo, o Gabriel Grasset — tiene mala apariencia en relación con un volumen producido por un maestro parisino como Michel-Antoine David o Jean-Baptiste Garnier. En otras palabras, compararía el primero con una olla de barro y el segundo, con un vaso de cristal. En aquella época, durante los inicios de la sociedad de consumo, el gran público prefería el libro poco caro y los falsificados invadían el mercado. Los archivos de la dirección de Librería abundan en memorias que indican que el comercio de libros «no es más que una piratería». Los inventarios de las librerías provinciales estaban compuestos esencialmente de falsificaciones. En 1778, un experto estimaba que sumaban al menos treinta millones, más de la mitad de los libros disponibles en el mercado.

La piratería representó, entonces, la democratización del acceso del pueblo francés a la literatura. No es que los piratas fueran idealistas, 
pese a que publicaron casi todos los libros de los philosophes, que no podían pasar la censura. Ellos querían ganar dinero, «el gran móvil de todo", como lo expresó un falsificador de Neuchâtel. Tras leer varios centenares de sus cartas, veo en ellos un capitalismo salvaje, en que las intrigas y engaños recuerdan Las ilusiones perdidas de Balzac. Aun así, un falsificador en Yverdon defendía su trabajo desde el punto de vista de la humanidad: "Todo librero o impresor que, mediante falsificaciones, procura expandir más abundante y prontamente los buenos libros, merece mucho de la humanidad».

Esta reflexión me hizo pensar en los problemas actuales de la democratización. En los Estados Unidos, la democracia anda mal y la información parece problemática. Las redes sociales deforman la comunicación, mientras que las grandes corporaciones - Google, Facebook, Twittermonopolizan el acceso. No insinúo que Google domina el mundo del libro de la misma manera que la comunidad de libreros e impresores de París en el siglo XVIII, pero, en mi opinión, representa un peligro.

Cuando Google lanzó su proyecto de digitalizar todos los libros del mundo, propuso solo un servicio de investigación y pidió comenzar por la biblioteca de Harvard, que posee la más grande biblioteca universitaria del mundo. Le cedimos el permiso para los libros que estaban en el ámbito público. Cuando propuso digitalizar los libros protegidos por derechos de autor, respondimos con un no definitivo. En tanto director de la Biblioteca en esa época, creí que era necesario respetar los derechos de autor; sin embargo, otras bibliotecas permitieron a Google digitalizar sus colecciones completas. De inmediato, los editores y autores presentaron sus quejas. Tras cerca de tres ańos de negociaciones, llegaron a un acuerdo: Google Book Search, que convirtió el servicio de investigación en una biblioteca comercial, cuyos ingresos serían compartidos por los autores, los editores y Google.

Veía en esto la amenaza de una nueva especie de monopolio: el acceso a la literatura en formato digital. Me involucré en una polémica contra Google y, para mi gran felicidad, una corte federal proscribió Google Book Search por ser una violación de las leyes que prohíben los monopolios. Tras el fallo, respondimos con la creación de la Digital Public 